\title{
A Population-based Study on Lymph Node Retrieval in Patients with Esophageal Cancer: Results from the Dutch Upper Gastrointestinal Cancer Audit
}

\author{
L. R. van der Werf, MD ${ }^{1}$, J. L. Dikken, MD, $\mathrm{PhD}^{2}$, M. I. van Berge Henegouwen, MD, $\mathrm{PhD}^{3}$, V. E. P. P. Lemmens, \\ $\mathrm{PhD}^{4}$, G. A. P. Nieuwenhuijzen, $\mathrm{MD}$, $\mathrm{PhD}^{5}$, B. P. L. Wijnhoven, MD, $\mathrm{PhD}^{1}$ on behalf of the Dutch Upper GI Cancer \\ Audit group \\ ${ }^{1}$ Department of Surgery, Erasmus University Medical Centre, Rotterdam, The Netherlands; ${ }^{2}$ Department of Surgery, \\ Leiden University Medical Centre, Leiden, The Netherlands; ${ }^{3}$ Department of Surgery, Amsterdam Medical Centre, \\ Amsterdam, The Netherlands; ${ }^{4}$ Department of Epidemiology, Erasmus University Medical Centre, Rotterdam, The \\ Netherlands; ${ }^{5}$ Department of Surgery, Catherina Hospital, Eindhoven, The Netherlands
}

\begin{abstract}
Background. For esophageal cancer, the number of retrieved lymph nodes (LNs) is often used as a quality indicator. The aim of this study is to analyze the number of retrieved LNs in The Netherlands, assess factors associated with LN yield, and explore the association with short-term outcomes. This is a population-based study on lymph node retrieval in patients with esophageal cancer, presenting results from the Dutch Upper Gastrointestinal Cancer Audit. Study Design. For this retrospective national cohort study, patients with esophageal carcinoma who underwent esophagectomy between 2011 and 2016 were included. The primary outcome was the number of retrieved LNs. Univariable and multivariable regression analyses were used to test for association with $\geq 15$ LNs.

Patients and Results. 3970 patients were included. Between 2011 and 2016, the median number of LNs increased from 15 to 20 . Factors independently associated
\end{abstract}

Collaborators of the Dutch Upper Gastrointestinal Cancer group are listed in "Acknowledgment".

Electronic supplementary material The online version of this article (https://doi.org/10.1245/s10434-018-6396-7) contains supplementary material, which is available to authorized users.

(C) The Author(s) 2018. This article is an open access publication

First Received: 12 December 2017;

Published Online: 9 March 2018

L. R. van der Werf, MD

e-mail: L.R.vdwerf@gmail.com with $\geq 15$ LNs were: $0-10 \mathrm{~kg}$ preoperative weight loss (versus: unknown weight loss, odds ratio [95\% confidence interval]: 0.71 [0.57-0.88]), Charlson score 0 (versus: Charlson score 2: 0.76 [0.63-0.92]), cN2 category (reference: cN0, 1.32 [1.05-1.65]), no neoadjuvant therapy and neoadjuvant chemotherapy (reference: neoadjuvant chemoradiotherapy, $1.73 \quad[1.29-2.32]$ and 2.15 [1.54-3.01]), minimally invasive transthoracic (reference: open transthoracic, 1.46 [1.15-1.85]), open transthoracic (versus open and minimally invasive transhiatal, 0.29 [0.23-0.36] and $0.43[0.32-0.59])$, hospital volume of 26-50 or $>50$ resections/year (reference: 0-25, 1.94 [1.55-2.42] and 3.01 [2.36-3.83]), and year of surgery [reference: 2011, odds ratios (ORs) 1.48, 1.53, 2.28, 2.44, 2.54]. There was no association of $\geq 15$ LNs with shortterm outcomes.

Conclusions. The number of LNs retrieved increased between 2011 and 2016. Weight loss, Charlson score, cN category, neoadjuvant therapy, surgical approach, year of resection, and hospital volume were all associated with increased LN yield. Retrieval of $\geq 15$ LNs was not associated with increased postoperative morbidity/mortality.

Since the relationship between the number of retrieved LNs and survival was shown, the number of retrieved lymph nodes (LNs) has often been used as a quality indicator for esophageal cancer surgery. ${ }^{1-5}$

In 2013, the total number of retrieved LNs was introduced as one of the quality indicators in the Dutch Upper Gastrointestinal Cancer Audit (DUCA). ${ }^{6}$ This nationwide audit aims to provide insight into the quality of delivered 
care by reporting reliable and benchmarked information on process and outcome parameters, defined as "quality indicators." The 7th edition of the Union for International Cancer Control (UICC)/American Joint Committee on Cancer (AJCC) classification recommended removal of at least $15 \mathrm{LNs}$ for reliable staging of gastric cancer. ${ }^{7}$ Hence, the number of 15 nodes was introduced as a quality indicator for esophageal cancer.

It is unclear whether introduction of this indicator resulted in higher LN yield. Furthermore, it is unknown which factors are associated with the number of LNs retrieved and whether higher $\mathrm{LN}$ yield is associated with higher postoperative morbidity or mortality.

The aim of this study is to evaluate trends in the number of retrieved lymph nodes and the proportion of patients with $\geq 15 \mathrm{LNs}$ in the resection specimen. The second aim is to identify patient, tumor, and treatment factors associated with the number of retrieved LNs, LN yield, and thirdly, to evaluate whether higher $\mathrm{LN}$ yield is associated with increased morbidity and/or 30-day/in-hospital mortality.

\section{METHODS}

\section{Study Design}

Data were retrieved from the DUCA. This surgical audit was initiated in 2011 and is part of the Dutch Institute for Clinical Auditing (DICA). All patients with esophageal or gastric cancer with intent of resection should be registered. Results on quality indicators are reported to the participating hospitals. Each year, external quality indicators are made transparent to the public, policy-makers, insurance companies, and patient federations. Validation of completeness and accuracy of data registration is performed. ${ }^{6}$ For this study, patient, tumor, and treatment characteristics, pathological information, and postoperative outcome (until 30 days after operation) were retrieved from the DUCA. Because patient and hospital identity are anonymous in the database, it was not possible to retrieve missing data or additional variables in retrospect.

\section{Patient Selection}

All patients undergoing surgery for esophageal cancer with curative intention between 2011 and 2016 were included. Patients with unknown date of birth, unknown survival status at 30 days after surgery or discharge (in case of hospital stay $>30$ days), or with unknown number of retrieved LNs were excluded.

Since 2010, nCRT followed by surgery has been the standard treatment according to the Dutch guideline for esophageal carcinoma (with the exception of T1N0 tumors). ${ }^{8}$

\section{Outcomes}

Primary outcomes were the number of retrieved LNs (as documented by the pathologist based on examination of the resection specimen) and the percentage of patients with $\geq 15$ LNs retrieved (as defined by the number of patients with at least 15 retrieved LNs relative to the total number of patients who underwent resection).

No informed consent or ethical approval was required under Dutch law.

\section{Statistical Analysis}

To compare patient, tumor, and treatment characteristics and surgical outcomes between the groups with $\geq 15 \mathrm{LNs}$ and with $<15$ LNs, the $\chi^{2}$ test was used. To identify associated factors, univariable and multivariable logistic regression analyses were performed. Factors with $P$ value $<0.10$ on univariable analyses or clinically relevant were included in multivariable analyses. For all analyses, statistical significance was defined as $P<0.05$. All analyses were performed using SPSS ${ }^{\circledR}$ version 24 (IBM, Armonk, NY, USA) and R (R Studio, version 0.99.903, Inc., with package "ggplot2").

Possible factors associated with LN yield were selected by the scientific committee of the DUCA based on literature. Consensus was reached for the factors age, preoperative weight loss, Body Mass Index (BMI), tumor location, American Society of Anesthesiologists (ASA) score, Charlson comorbidity score, ${ }^{9}$ clinical T-, N-, and M-category of the tumor, neoadjuvant chemo(radio)therapy, surgical approach (minimally invasive or open, and transhiatal or transthoracic), annual hospital volume, and year of surgery. For evaluation of minimally invasive approaches, stratified multivariable analysis for transhiatal and transthoracic was used. To assess the relationship between $\geq 15$ LNs and surgical outcomes, yield of $\geq 15$ LNs was analyzed in relation to nonradicality of the resection (resection margins not free of tumor cells), intraoperative complications, postoperative complications, and 30-day and/or in-hospital mortality. A severe complication was defined as a complication leading to hospital stay $>21$ days, reintervention or death.

\section{RESULTS}

A total of 4076 patients who underwent esophagectomy for esophageal carcinoma were registered in the DUCA between 2011 and 2016. Some patients were excluded because date of birth was missing $(n=12)$, survival status after 30 days/at discharge was missing $(n=80)$, or the number of LNs was not documented $(n=14)$. Hence, a 
total of 3970 patients was included in the study analyses (Supplementary Fig. S1).

\section{Number of Retrieved LNs}

The median number of retrieved LNs increased from 15 [interquartile range (IQR) 10-21] in 2011 to 20 (IQR 16-27) in 2016 (Fig. 1). Overall, the percentage of patients with $\geq 15 \mathrm{LNs}$ was $69 \%$. Among patients with $\geq 15 \mathrm{LNs}$, the median number of retrieved LNs was 22 (IQR 18-28), and in the group of patients with $<15 \mathrm{LNs}$, this number was 11 (IQR $8-13$ ). The percentage of patients with $\geq 15$ retrieved LNs increased from $51 \%$ in 2011 to $81 \%$ in 2016 . In 2011 , the percentage of patients with $\geq 15$ retrieved LNs ranged between 0 and $77 \%$ among hospitals. In 2016, this variation between hospitals decreased (Fig. 2).

\section{Factors Associated with $\geq 15$ LNs}

Patient, tumor, treatment, and hospital characteristics are presented in Table 1 . Factors associated with $<15 \mathrm{LNs}$ were Charlson score 2 (reference: Charlson score 0, 0.76 [0.63-0.92]) and unknown preoperative weight loss (reference: $0-10 \mathrm{~kg}$ weight loss, odds ratio [95\% confidence interval] 0.71 [0.57-0.88]) (Table 2).

Factors associated with $\geq 15$ LNs were clinical N2 category (reference: clinical N0, 1.32 [1.05-1.65]), no neoadjuvant therapy and neoadjuvant chemotherapy (reference neoadjuvant chemoradiotherapy, 1.73 [1.29-2.32] and 2.15 [1.54-3.01]), resection in a hospital with $26-50$ or $>50$ resections per year (reference: $0-25$ resections, 1.94 [1.55-2.42] and 3.01 [2.36-3.83]), and resection between 2012 and 2016 (reference: 2011, ORs 1.48 [1.13-1.94],
1.53 [1.17-2.00], 2.28 [1.73-3.00], 2.44 [1.85-3.21], and 2.54 [1.91-3.39] for the years 2012 through 2016).

Transthoracic (open or minimally invasive) approach was associated with a higher percentage of patients with $\geq 15 \mathrm{LNs}$ (versus open or minimally invasive transhiatal approach, 0.29 [0.23-0.36] and 0.43 [0.32-0.59]).

Stratified multivariable analysis for transthoracic resections showed a statistically significant association of minimally invasive approach with yield $\geq 15$ LNs (reference: open transthoracic approach, 1.46 [1.15-1.85]). There was no such association for minimally invasive transhiatal resection with $\geq 15$ LNs (reference: open transhiatal resection, 1.31 [0.97-1.75]).

\section{LN Yield in Relation to Short-term Surgical Outcomes}

Table 3 presents the association of $\geq 15 \mathrm{LNs}$ with shortterm outcomes (with $<15$ LNs as reference group). LN yield $\geq 15$ was independently associated with fewer intraoperative complications $(4.5 \%$ vs. $6.8 \%$, OR 0.69 [0.50-0.95]). Postoperative complications were more frequent in patients with $\geq 15$ LNs than in patients with $<15$ LN, but multivariable analysis showed no statistically significant association (Table 3).

\section{DISCUSSION}

Between 2011 and 2016, the percentage of patients with at least 15 retrieved LNs in esophageal cancer surgery increased on a national level as well as for the individual hospitals.

Our results show an association of $\geq 15$ LNs with higher clinical $\mathrm{N}$-category. It may be possible that, in

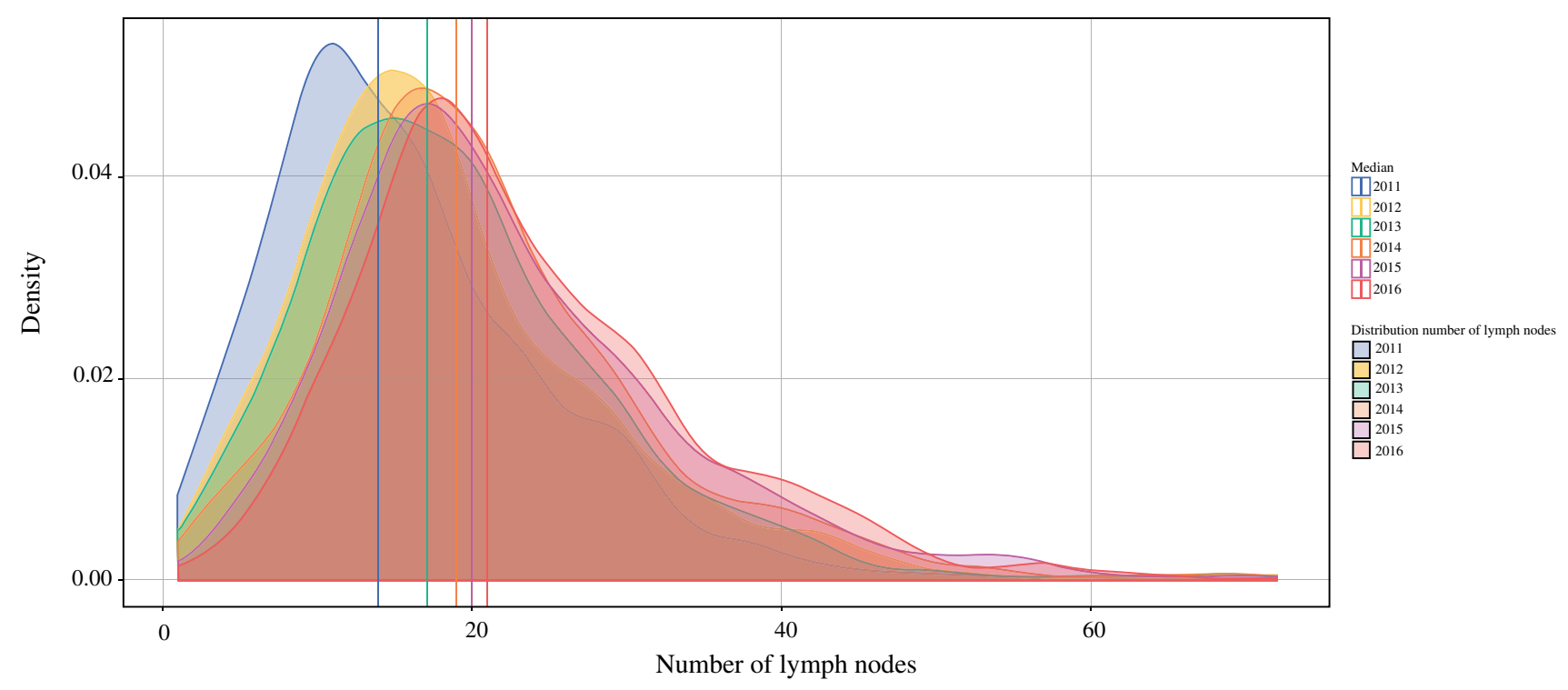

FIG. 1 Density plot showing distribution of absolute number of LNs retrieved from 2011 to 2016 
FIG. 2 Variation in hospital score on the quality indicator "retrieval of at least 15 LNs"

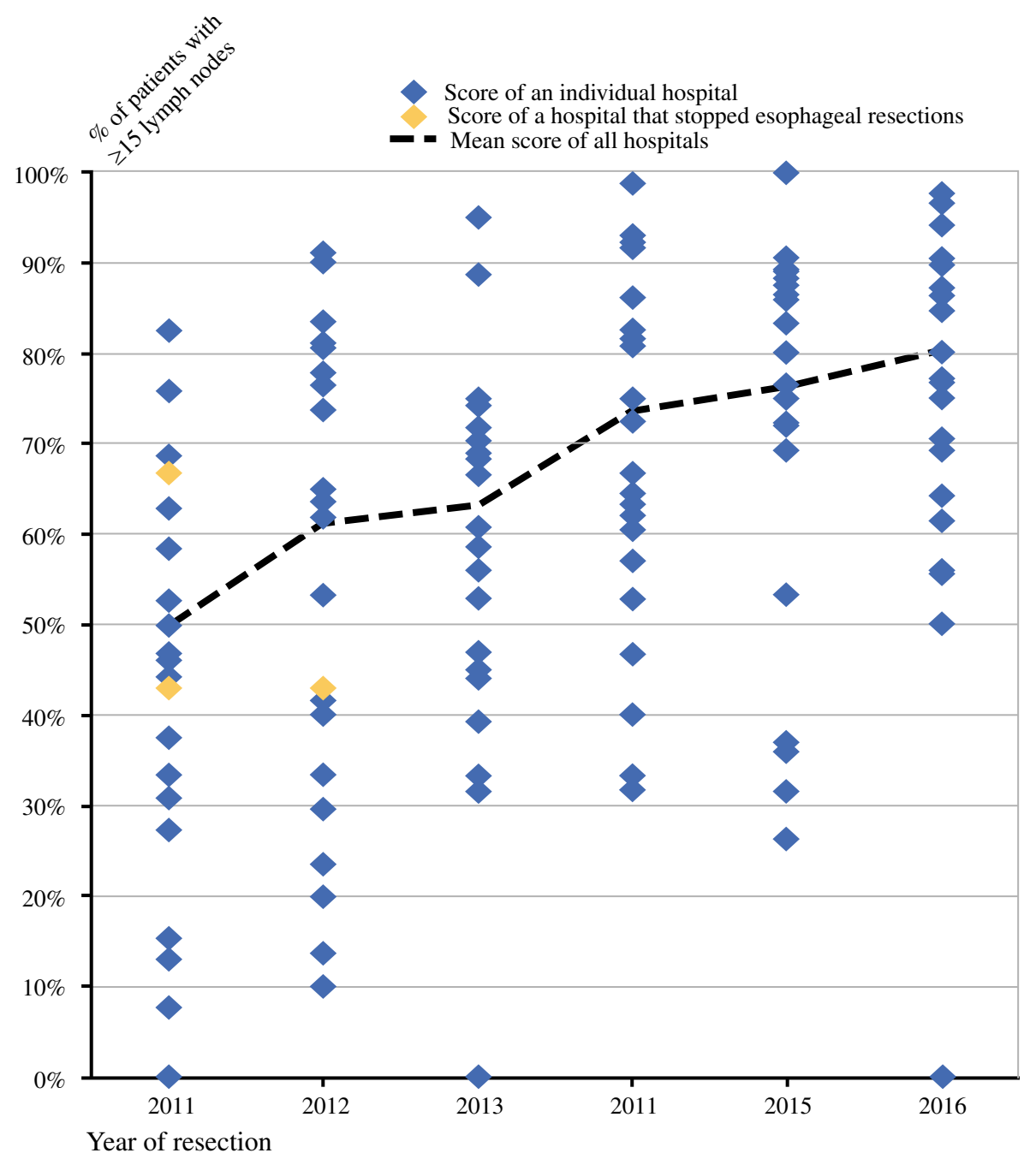

patients with clinically suspicious positive lymph nodes, the surgeon is particularly focused on more complete LN dissection. Also, tumor-positive LNs are often increased in size and therefore easier to identify during the operation and during pathological examination of the resection specimen. This could result in a higher number of retrieved LNs. Another explanation is that the immune response against the tumor influences the number of retrieved LNs. It has been suggested that larger tumors may cause a more intense immune response, leading to hyperplasia of local LNs, which could increase LN detectability. ${ }^{10}$ However, this hypothesis is not proven yet.

It is well known that the type of surgical approach in esophageal resection influences the number of retrieved LNs; i.e., transthoracic as compared with transhiatal approach is associated with a higher number of LNs retrieved, as also seen in the current study. ${ }^{11,12}$ Regarding the impact of a minimally invasive approach on LN yield, conflicting results have been published. A systematic review showed no differences between open and minimally invasive surgery, while another meta-analysis showed significantly higher LN retrieval in minimally invasive surgery (16 vs. $10, P=0.03){ }^{13,14}$ In the present study, higher LN retrieval was seen especially in minimally invasive transthoracic procedures, which is in accordance with a recent propensity-score-matched analysis also using data from the DUCA [20 (2-59) vs. $18(0-53)$ LNs; $P<0.001] .{ }^{15}$ It is possible that minimally invasive surgery offers benefits in terms of magnification and visibility of surgical structures and planes, which may translate into higher LN yield.

Busweiler et al. recently showed that, in patients undergoing gastrectomy, the percentage of patients with $\geq 15$ retrieved LNs was higher in hospitals with higher composite hospital volume (gastrectomies, esophagectomies, and pancreatectomies). ${ }^{16}$ In our study, a similar association was noticed for esophageal cancer surgery. It is suggested that hospitals performing this type of surgery may benefit from the in-hospital experience. ${ }^{16}$ More 
TABLE 1 Basic characteristics of study population, including score of $\%$ of patients with $\geq 15$ lymph nodes for each subgroup

\begin{tabular}{|c|c|c|c|c|}
\hline \multirow[t]{2}{*}{ Patient characteristic } & \multirow[t]{2}{*}{ Total $n(\%)$} & \multicolumn{3}{|c|}{ Results on the quality indicator } \\
\hline & & $<15 \mathrm{LNs}$ & $\geq 15 \mathrm{LNs}$ & $P$ value* \\
\hline Total & 3970 & $31 \%$ & $69 \%$ & \\
\hline Gender & & & & 0.83 \\
\hline Male & $3077(78 \%)$ & $31 \%$ & $69 \%$ & \\
\hline Female & $892(23 \%)$ & $31 \%$ & $69 \%$ & \\
\hline Unknown & $1(0.0 \%)$ & $0 \%$ & $100 \%$ & \\
\hline Age (in years) & & & & 0.002 \\
\hline $0-64$ & $1787(45 \%)$ & $29 \%$ & $71 \%$ & \\
\hline $65-74$ & $1650(42 \%)$ & $31 \%$ & $69 \%$ & \\
\hline $75+$ & $533(13 \%)$ & $37 \%$ & $63 \%$ & \\
\hline Preoperative weight loss (kg) & & & & $<0.001$ \\
\hline $0-5$ & $2154(54 \%)$ & $29 \%$ & $71 \%$ & \\
\hline $6-10$ & $835(21 \%)$ & $31 \%$ & $69 \%$ & \\
\hline $10+$ & $443(11 \%)$ & $33 \%$ & $67 \%$ & \\
\hline Unknown & $538(14 \%)$ & $38 \%$ & $62 \%$ & \\
\hline Body Mass Index $\left(\mathrm{kg} / \mathrm{m}^{2}\right)$ & & & & 0.48 \\
\hline$<20$ & $257(6.5 \%)$ & $34 \%$ & $66 \%$ & \\
\hline $20-24$ & $1512(38 \%)$ & $31 \%$ & $70 \%$ & \\
\hline $25-29$ & $1522(38 \%)$ & $30 \%$ & $70 \%$ & \\
\hline $30+$ & $635(16 \%)$ & $33 \%$ & $67 \%$ & \\
\hline Unknown & $44(1.1 \%)$ & $41 \%$ & $59 \%$ & \\
\hline $\begin{array}{l}\text { Tumor location in } \\
\text { esophagus }\end{array}$ & & & & $<0.001$ \\
\hline Cervical & $4(0.1 \%)$ & $50 \%$ & $50 \%$ & \\
\hline Proximal & $40(1.0 \%)$ & $15 \%$ & $85 \%$ & \\
\hline Mid & $486(12 \%)$ & $25 \%$ & $76 \%$ & \\
\hline Distal & $2504(63 \%)$ & $31 \%$ & $69 \%$ & \\
\hline Gastroesophageal junction & $936(24 \%)$ & $36 \%$ & $65 \%$ & \\
\hline ASA score & & & & 0.08 \\
\hline $\mathrm{I}-\mathrm{II}$ & $3070(77 \%)$ & $30 \%$ & $70 \%$ & \\
\hline $\mathrm{III}+$ & $880(22 \%)$ & $33 \%$ & $67 \%$ & \\
\hline Unknown & $20(0.5 \%)$ & $50 \%$ & $50 \%$ & \\
\hline Charlson score & & & & 0.002 \\
\hline 0 & $1939(49 \%)$ & $29 \%$ & $71 \%$ & \\
\hline 1 & $1012(26 \%)$ & $31 \%$ & $69 \%$ & \\
\hline $2+$ & $1019(26 \%)$ & $35 \%$ & $65 \%$ & \\
\hline Clinical T-category & & & & 0.63 \\
\hline cT0-1 & $209(5.3 \%)$ & $29 \%$ & $71 \%$ & \\
\hline cT2 & $736(19 \%)$ & $33 \%$ & $67 \%$ & \\
\hline cT3 & $2731(69 \%)$ & $31 \%$ & $69 \%$ & \\
\hline cT4 & $135(3.4 \%)$ & $29 \%$ & $71 \%$ & \\
\hline Unknown & $159(4.0 \%)$ & $31 \%$ & $69 \%$ & \\
\hline Clinical N-category & & & & 0.001 \\
\hline cNO & $1407(35 \%)$ & $33 \%$ & $67 \%$ & \\
\hline $\mathrm{cN} 1$ & $1591(40 \%)$ & $31 \%$ & $69 \%$ & \\
\hline $\mathrm{cN} 2$ & $716(18 \%)$ & $26 \%$ & $74 \%$ & \\
\hline $\mathrm{cN} 3$ & $100(2.5 \%)$ & $25 \%$ & $75 \%$ & \\
\hline $\mathrm{cN}+($ count unknown $)$ & $42(1.1 \%)$ & $29 \%$ & $71 \%$ & \\
\hline
\end{tabular}


TABLE 1 continued

\begin{tabular}{|c|c|c|c|c|}
\hline \multirow[t]{2}{*}{ Patient characteristic } & \multirow[t]{2}{*}{ Total $n(\%)$} & \multicolumn{3}{|c|}{ Results on the quality indicator } \\
\hline & & $<15 \mathrm{LNs}$ & $\geq 15 \mathrm{LNs}$ & $P$ value* \\
\hline Unknown & $114(2.9 \%)$ & $45 \%$ & $55 \%$ & \\
\hline Clinical M-category & & & & 0.85 \\
\hline cM0 & $3837(97 \%)$ & $31 \%$ & $69 \%$ & \\
\hline cM1 & $34(0.9 \%)$ & $29 \%$ & $71 \%$ & \\
\hline Unknown & $99(2.5 \%)$ & $34 \%$ & $66 \%$ & \\
\hline Neoadjuvant therapy & & & & 0.05 \\
\hline No & $324(8.2 \%)$ & $28 \%$ & $73 \%$ & \\
\hline Chemotherapy & $253(6.4 \%)$ & $26 \%$ & $74 \%$ & \\
\hline Chemoradiotherapy & $3373(85 \%)$ & $32 \%$ & $68 \%$ & \\
\hline Surgical approach & & & & $<0.001$ \\
\hline TTE thoracic part open & $694(18 \%)$ & $27 \%$ & $73 \%$ & \\
\hline TTE thoracic part MI & $1984(50 \%)$ & $18 \%$ & $82 \%$ & \\
\hline THE open & $935(24 \%)$ & $56 \%$ & $44 \%$ & \\
\hline THE MI & $344(8.7 \%)$ & $45 \%$ & $55 \%$ & \\
\hline Unknown & $13(0.3 \%)$ & $69 \%$ & $31 \%$ & \\
\hline Salvage resection & & & & 0.75 \\
\hline No & $3870(98 \%)$ & $31 \%$ & $69 \%$ & \\
\hline Yes & $55(1.4 \%)$ & $29 \%$ & $71 \%$ & \\
\hline Unknown & $45(1.1 \%)$ & $29 \%$ & $71 \%$ & \\
\hline $\begin{array}{l}\text { Hospital volume (average } \\
\text { number of resections/year) }\end{array}$ & & & & $<0.001$ \\
\hline $0-25$ & $522(13 \%)$ & $53 \%$ & $47 \%$ & \\
\hline $26-50$ & $2194(55 \%)$ & $29 \%$ & $71 \%$ & \\
\hline $50+$ & $1229(31 \%)$ & $24 \%$ & $76 \%$ & \\
\hline Stopped before 2014 & $25(0.6 \%)$ & $76 \%$ & $24 \%$ & \\
\hline Year of resection & & & & $<0.001$ \\
\hline 2011 & $491(12 \%)$ & $50 \%$ & $50 \%$ & \\
\hline 2012 & $613(15 \%)$ & $39 \%$ & $62 \%$ & \\
\hline 2013 & $641(16 \%)$ & $37 \%$ & $63 \%$ & \\
\hline 2014 & $702(18 \%)$ & $26 \%$ & $74 \%$ & \\
\hline 2015 & $778(20 \%)$ & $24 \%$ & $76 \%$ & \\
\hline 2016 & $745(19 \%)$ & $20 \%$ & $80 \%$ & \\
\hline
\end{tabular}

ASA American Society of Anesthesiologists, TTE transthoracic esophagectomy, THE transhiatal esophagectomy, MI minimally invasive, $L N s$ lymph nodes

*Chi-squared analysis, in case of $<5 \%$ "unknown," this category was not included in the statistical analysis (exception: cN-category)

intensive cooperation of a multidisciplinary team could be important for quality improvement initiatives.

This study showed an increase in the number of LNs every year. It is expected that, since the introduction of quality indicators in the DUCA, quality improvement initiatives in all hospitals have been initiated, because the results of these indicators are transparent for all individual hospitals each year. The national healthcare inspectorate, health insurance authorities, and different federations use the outcomes of this indicator to assess the quality of upper gastrointestinal surgical care in hospitals in The Netherlands. The increased numbers of retrieved LNs over the years could be the result of increased awareness of the importance of LN dissection by surgeons. On the other hand, back table dissection of the specimen and more extensive pathological assessment as a result of dedication of the pathologist could be major explanations as well. All these explanations have likely contributed to improving quality of care. The role of the pathologists in identifying nodes in the resection specimen is very important, as the 
TABLE 2 Multivariable logistic regression analysis for factors associated with $\geq 15 \mathrm{LNs}$

\begin{tabular}{|c|c|c|c|c|}
\hline \multirow{2}{*}{$\begin{array}{l}\text { Characteristic } \\
\text { Total }\end{array}$} & \multirow{2}{*}{$\begin{array}{l}n \\
3970\end{array}$} & \multicolumn{3}{|c|}{ Multivariable analysis } \\
\hline & & $P$ value & OR & $95 \% \mathrm{CI}$ \\
\hline Age (years) & & 0.29 & & \\
\hline $0-64$ & 1756 & & ref & \\
\hline $65-74$ & 1615 & 0.67 & 0.96 & $0.82-1.14$ \\
\hline $75+$ & 521 & 0.12 & 0.83 & $0.66-1.05$ \\
\hline Preoparative weight loss (kg) & & 0.01 & & \\
\hline $0-10$ & 2938 & & ref & \\
\hline $10.1-15$ & 261 & 0.12 & 0.79 & $0.59-1.06$ \\
\hline$>15$ & 174 & 0.19 & 0.78 & $0.54-1.13$ \\
\hline Unknown & 519 & $<0.001$ & 0.71 & $0.57-0.88$ \\
\hline Tumor location in esophagus & & 0.59 & & \\
\hline Cervical & 4 & 0.41 & 0.40 & $0.05-3.46$ \\
\hline Proximal & 39 & 0.22 & 1.80 & $0.71-4.54$ \\
\hline Mid & 480 & 0.68 & 0.95 & $0.74-1.22$ \\
\hline Distal & 2451 & & ref & \\
\hline Gastroesophageal junction & 918 & 0.59 & 1.05 & $0.87-1.27$ \\
\hline ASA score & & 0.77 & & \\
\hline I-II & 3020 & & ref & \\
\hline III+ & 872 & & 1.03 & $0.85-1.24$ \\
\hline Charlson score & & 0.02 & & \\
\hline 0 & 1897 & & ref & \\
\hline 1 & 998 & 0.68 & 0.96 & $0.80-1.16$ \\
\hline $2+$ & 997 & 0.01 & 0.76 & $0.63-0.92$ \\
\hline Clinical N-category & & 0.02 & & \\
\hline cNO & 1383 & & ref & \\
\hline $\mathrm{cN} 1$ & 1553 & 0.37 & 1.08 & $0.91-1.29$ \\
\hline $\mathrm{cN} 2$ & 707 & 0.02 & 1.32 & $1.05-1.65$ \\
\hline $\mathrm{cN} 3$ & 99 & 0.15 & 1.47 & $0.87-2.48$ \\
\hline $\mathrm{cN}+($ count unknown $)$ & 41 & 0.30 & 1.50 & $0.70-3.19$ \\
\hline Unknown & 109 & 0.07 & 0.67 & $0.43-1.03$ \\
\hline Neoadjuvant therapy & & $<0.001$ & & \\
\hline No & 322 & $<0.001$ & 1.73 & $1.29-2.32$ \\
\hline Chemotherapy & 249 & $<0.001$ & 2.15 & $1.54-3.01$ \\
\hline Chemoradiotherapy & 3321 & & ref & \\
\hline Surgical approach & & $<0.001$ & & \\
\hline TTE thoracic part open (incl. MI abdomen) & 686 & & ref & \\
\hline TTE thoracic part MI & 1968 & 0.004 & 1.38 & $1.11-1.73$ \\
\hline THE open & 912 & $<0.001$ & 0.29 & $0.23-0.36$ \\
\hline THE MI & 326 & $<0.001$ & 0.43 & $0.32-0.59$ \\
\hline Hospital volume (average number of resections/year) & & $<0.001$ & & \\
\hline $0-25$ & 506 & & ref & \\
\hline $26-50$ & 2174 & $<0.001$ & 1.94 & $1.55-2.42$ \\
\hline$>50$ & 1212 & $<0.001$ & 3.01 & $2.36-3.83$ \\
\hline Year of resection & & $<0.001$ & & \\
\hline 2011 & 462 & & ref & \\
\hline 2012 & 599 & 0.01 & 1.48 & $1.13-1.94$ \\
\hline 2013 & 616 & 0.00 & 1.53 & $1.17-2.00$ \\
\hline 2014 & 699 & $<0.001$ & 2.28 & $1.73-3.00$ \\
\hline
\end{tabular}


TABLE 2 continued

\begin{tabular}{llllr}
\hline Characteristic & $n$ & \multicolumn{3}{l}{ Multivariable analysis } \\
\cline { 3 - 5 } Total & 3970 & $P$ value & OR & $95 \%$ CI \\
\hline 2015 & 774 & $<0.001$ & 2.44 & $1.85-3.21$ \\
2016 & 742 & $<0.001$ & 2.54 & $1.91-3.39$ \\
\hline
\end{tabular}

ASA American Society of Anesthesiologists, TTE transthoracic esophagectomy, THE transhiatal esophagectomy, $M I$ minimally invasive, $O R$ odds ratio, $C I$ confidence interval

TABLE 3 Surgical outcomes associated with $\geq 15$ LNs

\begin{tabular}{|c|c|c|c|c|c|c|}
\hline \multirow[t]{3}{*}{ Outcomes } & \multirow{3}{*}{$\begin{array}{l}<15 \mathrm{LNs} \% \\
(n)\end{array}$} & \multirow{3}{*}{$\begin{array}{l}\geq 15 \text { LNs } \% \\
(n)\end{array}$} & \multicolumn{2}{|l|}{ Univariable analysis } & \multicolumn{2}{|l|}{ Multivariable analysis } \\
\hline & & & \multicolumn{4}{|c|}{ (with outcomes as dependent variable) } \\
\hline & & & $\begin{array}{l}\text { OR }[95 \% \text { CI }] \geq 15 \\
\text { LNs }\end{array}$ & $P$ value & $\begin{array}{l}\text { OR }[95 \% \text { CI }] \geq 15 \\
\text { LNs }\end{array}$ & $P$ value \\
\hline Positive resection margins & $5.6 \%(68)$ & $4.9 \%(132)$ & $1.16[0.86-1.57]$ & 0.33 & & \\
\hline Intraoperative complications & $6.8 \%(83)$ & $4.5 \%(122)$ & $0.64[0.48-0.86]$ & 0.003 & $0.69[0.50-0.95]^{\wedge}$ & 0.02 \\
\hline Bleeding (with transfusion) & $22 \%(18)$ & $16 \%(20)$ & & & & \\
\hline Intestinal injury & $9.6 \%(8)$ & $5.8 \%(7)$ & & & & \\
\hline Spleen injury & $13 \%(11)$ & $17 \%(20)$ & & & & \\
\hline Other & $55 \%(46)$ & $61 \%(75)$ & & & & \\
\hline Postoperative complications & $57 \%(702)$ & $61 \%(1667)$ & $1.17[1.02-1.34]$ & 0.02 & $1.01[0.93-1.27]^{*}$ & 0.28 \\
\hline Pulmonary & $29 \%(356)$ & $32 \%(879)$ & & & & \\
\hline Cardiac & $12 \%(150)$ & $15 \%(401)$ & & & & \\
\hline $\begin{array}{l}\text { Anastomotic leakage/local necrosis } \\
\text { conduit }\end{array}$ & $20 \%(241)$ & $18 \%(503)$ & & & & \\
\hline Chylous leakage & $5 \%(58)$ & $8 \%(240)$ & & & & \\
\hline Severe postoperative complications & $28 \%(339)$ & $31 \%(847)$ & $1.18[1.01-1.37]$ & 0.03 & $1.00[0.85-1.19]^{*}$ & 0.98 \\
\hline 30-day/in-hospital mortality & $4.2 \%(52)$ & $3.5 \%(95)$ & $0.82[0.58-1.15]$ & 0.24 & & \\
\hline
\end{tabular}

ASA American Surgical Association, LNs lymph nodes, OR odds ratio, CI confidence interval

$\wedge$ Adjusted for: Body Mass Index, ASA score, surgical approach, year of resection

*Adjusted for: age, Body Mass Index, Charlson score, ASA score, histological type, tumor location, surgical approach, hospital volume

time spent doing this makes a great difference. ${ }^{17}$ In this study, the role of the pathologist could not be studied, but dedicated pathologists or technicians are associated with increased number of nodes detected. ${ }^{18,19}$

More extensive LN dissection may lead to better locoregional tumor control. However, the importance of LN dissection for locoregional tumor control has been debated since the introduction of neoadjuvant chemoradiotherapy. It is known that neoadjuvant chemoradiotherapy leads to tumor and lymph node downstaging, resulting in more resections with negative margins and lymph nodes. ${ }^{20}$ The study of Talsma et al. showed that the number of retrieved LNs had a prognostic impact for patients who underwent surgery without neoadjuvant chemoradiotherapy, but not in the group of patients who underwent neoadjuvant chemoradiotherapy. ${ }^{21}$ For patients treated with neoadjuvant chemotherapy, Markar et al. also showed lower recurrence rate and improved survival for patients with higher lymph node yield. Similarly, effects of higher lymph node yield on survival or recurrence were not observed in patients treated with neoadjuvant chemoradiotherapy. ${ }^{22}$ In the current study, we observed an inverse correlation between neoadjuvant chemoradiotherapy and retrieved LNs, which has been reported before. ${ }^{11,21,23,24} \mathrm{An}$ explanation for this phenomenon could be that use of neoadjuvant chemoradiotherapy leads to less priority for extended LN dissection by Dutch surgeons, or that neoadjuvant treatment, especially neoadjuvant 
chemoradiotherapy, may induce regression of LNs, as reported before. ${ }^{10}$ So, despite radical resection, fewer LNs are retrieved or detected by the pathologist. Unfortunately, the DUCA registry has no long-term follow-up. Hence, it cannot be concluded from the results of this study whether the number of retrieved LNs is a valid indicator for the quality of locoregional tumor treatment. Nonetheless, this indicator may be meaningful as an indicator for overall quality of esophageal cancer care. Higher number of retrieved LNs may lead to improved tumor staging, and complete pathological staging is essential to predict the prognosis of patients. Furthermore, in patients treated with neoadjuvant chemoradiotherapy, signs of tumor regression in LNs (instead of positive LNs) are a better predictor of prognosis than clinical N-category, which is not always easy to assess preoperatively.

\section{CONCLUSIONS}

Pro and contra arguments can be provided for use of a minimal number of retrieved LNs as a quality indicator in clinical auditing. An argument for the use of this indicator in clinical auditing is that it reveals relevant variation in outcomes of hospitals, which seems to distinguish between them. Another advantage could be that this indicator may lead to better quality of esophageal cancer because of quality improvement initiatives. However, the validity of this indicator as a direct measure of the quality of $\mathrm{LN}$ dissection is questionable, and the effect of more retrieved LNs on tumor control is debatable since the introduction of neoadjuvant chemoradiotherapy. Nevertheless, higher lymph node retrieval does not seem to lead to higher morbidity or mortality, so the number of retrieved LNs can safely be used as an indicator for quality of care.

ACKNOWLEDGMENT The authors would like to thank all surgeons, registrars, physician assistants, and administrative nurses for data registration in the DUCA database.

Collaborators The following members of the DUCA group were collaborators in this study: K. Bosscha (Department of Surgery, Jeroen Bosch Hospital, 's-Hertogenbosch); N. C. T. van Grieken (Department of Pathology, VU University Medical Centre, Amsterdam); H. H. Hartgrink (Department of Surgery, Leiden University Medical Centre, Leiden); R. van Hillegersberg (Department of Surgery, University Medical Centre Utrecht, Utrecht); V. E. P. P. Lemmens (Department of Epidemiology, Erasmus University Medical Centre, Rotterdam, IKNL); J. T. Plukker (Department of Surgery, University Medical Centre Groningen, Groningen); C. Rosman (Department of Surgery, Radboud University Medical Centre, Nijmegen); J. W. van Sandick (Department of Surgical Oncology, the Netherlands Cancer Institute-Antoni van Leeuwenhoek Hospital, Amsterdam); P.D. Siersema (Department of Gastroenterology and Hepatology, Radboud University Medical Centre, Nijmegen); G. Tetteroo (Department of Surgery, IJsselland Ziekenhuis, Capelle a/d IJssel); P. M. J. F. Veldhuis (Department of Oncological Care, IKNL); F. E. M. Voncken (Department of Radiotherapy, The
Netherlands Cancer Institute-Antoni van Leeuwenhoek Hospital, Amsterdam).

DISCLOSURE The authors have declared no conflicts of interest.

OPEN ACCESS This article is distributed under the terms of the Creative Commons Attribution 4.0 International License (http:// creativecommons.org/licenses/by/4.0/), which permits unrestricted use, distribution, and reproduction in any medium, provided you give appropriate credit to the original author(s) and the source, provide a link to the Creative Commons license, and indicate if changes were made.

\section{REFERENCES}

1. Rizk NP, Ishwaran H, Rice TW, et al. Optimum lymphadenectomy for esophageal cancer. Ann Surg. 2010;251(1):46-50.

2. Peyre CG, Hagen JA, DeMeester SR, et al. The number of lymph nodes removed predicts survival in esophageal cancer: an international study on the impact of extent of surgical resection. Ann Surg. 2008;248(4):549-56.

3. Dutkowski P, Hommel G, Bottger T, Schlick T, Junginger T. How many lymph nodes are needed for an accurate $\mathrm{pN}$ classification in esophageal cancer? Evidence for a new threshold value. Hepatogastroenterology. 2002;49(43):176-80.

4. Solomon N, Zhuge Y, Cheung M, Franceschi D, Koniaris LG. The roles of neoadjuvant radiotherapy and lymphadenectomy in the treatment of esophageal adenocarcinoma. Ann Surg Oncol. 2010;17(3):791-803.

5. Hu Y, Hu C, Zhang H, Ping Y, Chen L-Q. How does the number of resected lymph nodes influence TNM staging and prognosis for esophageal carcinoma? Ann Surg Oncol. 2010;17(3):784-90.

6. Busweiler LA, Wijnhoven BP, van Berge Henegouwen MI, et al. Early outcomes from the Dutch Upper Gastrointestinal Cancer Audit. Br J Surg. 2016;103(13):1855-63.

7. Edge S, Byrd DR, Compton CC, Fritz AG, Greene F, Trotti A. AJCC cancer staging manual. Springer, New York; 2010.

8. Dutch Society of Gastroenterologists. Guideline esophagus carcinoma. Version 3.1. 2015.

9. Charlson ME, Pompei P, Ales KL, MacKenzie CR. A new method of classifying prognostic comorbidity in longitudinal studies: Development and validation. $J$ Chronic Dis. 1987;40(5):373-83.

10. Märkl B. Stage migration vs. immunology: the lymph node count story in colon cancer. World $J$ Gastroenterol. 2015;21(43):12218-33.

11. Hulscher JB, van Sandick JW, de Boer AG, et al. Extended transthoracic resection compared with limited transhiatal resection for adenocarcinoma of the esophagus. $N$ Engl J Med. 2002;347(21):1662-9.

12. Davies AR, Sandhu H, Pillai A, et al. Surgical resection strategy and the influence of radicality on outcomes in oesophageal cancer. Br J Surg. 2014;101(5):511-7.

13. Parry K, Ruurda JP, van der Sluis PC, van Hillegersberg R. Current status of laparoscopic transhiatal esophagectomy for esophageal cancer patients: a systematic review of the literature. Dis Esophagus. 2017;30(1):1-7.

14. Dantoc M, Cox MR, Eslick GD. Evidence to support the use of minimally invasive esophagectomy for esophageal cancer: a meta-analysis. Arch Surg. 2012;147(8):768-76.

15. Seesing MFJ, Gisbertz SS, Goense L, et al. A propensity score matched analysis of open versus minimally invasive transthoracic esophagectomy in the Netherlands. Ann Surg. 2017;266(5):839-46. 
16. Busweiler LA, Dikken JL, van Berge Henegouwen MI, et al. The influence of a composite hospital volume of upper gastrointestinal cancer resections on outcomes of gastric cancer surgery. J Clin Oncol. 2016;34(7_suppl):305.

17. de Burlet KJ, van den Hout MF, Putter H, Smit VT, Hartgrink $\mathrm{HH}$. Total number of lymph nodes in oncologic resections, is there more to be found? J Gastrointest Surg. 2015;19(5):943-8.

18. Choi JP, Park IJ, Lee BC, et al. Variability in the lymph node retrieval after resection of colon cancer: influence of operative period and process. Medicine (Baltimore). 2016. https://doi.org/ 10.1097/MD.0000000000004199.

19. Kuijpers CC, van Slooten HJ, Schreurs WH, et al. Better retrieval of lymph nodes in colorectal resection specimens by pathologists' assistants. J Clin Pathol. 2013;66(1):18-23.

20. van Hagen P, Hulshof MC, van Lanschot JJ, et al. Preoperative chemoradiotherapy for esophageal or junctional cancer. $N$ Engl $J$ Med. 2012;366(22):2074-84.
21. Talsma AK, Shapiro J, Looman CW, et al. Lymph node retrieval during esophagectomy with and without neoadjuvant chemoradiotherapy: prognostic and therapeutic impact on survival. Ann Surg. 2014;260(5):786-92; discussion 792-783.

22. Markar SR, Noordman BJ, Mackenzie H, et al. Multimodality treatment for esophageal adenocarcinoma: multi-center propensity-score matched study. Ann Oncol. 2017;28(3):519-27.

23. Hulscher JB, Tijssen JG, Obertop H, van Lanschot JJ. Transthoracic versus transhiatal resection for carcinoma of the esophagus: a meta-analysis. Ann Thorac Surg. 2001;72(1):306-13.

24. Robb WB, Dahan L, Mornex F, et al. Impact of neoadjuvant chemoradiation on lymph node status in esophageal cancer: post hoc analysis of a randomized controlled trial. Ann Surg. 2015;261(5):902-8. 